\title{
LANDUSE PLANNING FOR SOCIAL INCLUSION: AN ANALYSIS OF BANGALORE, INDIA
}

\author{
GARGI GHOSH \\ Urban Planning and Transportation Department, Sky Group, India
}

\begin{abstract}
This paper analyses the spatial plan/landuse plan of Bangalore for its effectiveness in bringing about social inclusion. The concept of social inclusion has been broadly based on the framework of Amartya Sen's theory of entitlement. Hence the paper adapts the definition of social inclusion as a function of access to social activities like employment, education, healthcare and leisure. Accessibility as a function of access to jobs is chosen as the indicator for evaluating social inclusion. The spatial plan of Bangalore, the Revised Master Plan 2015 (prepared in 2007) has been discussed here. The metropolitan regions plan has been evaluated at the composite level to arrive at appropriate landuse planning policy responses for social inclusion.
\end{abstract}

Keywords: accessibility, landuse planning, spatial planning, social inclusion, employment.

\section{INTRODUCTION}

Social Integration was one of the key concepts discussed in the Copenhagen world Summit for Social Development in 1995. The aim of the free world was agreed to create a "society for all". Right to an equitable society for all was consented as a moral duty. Amartya Sen's theory of entitlement provides the basis of the concept of social inclusion adopted in this paper. Amartya Sen's work was based on famines and especially the Great Bengal Famine of 1943 [1]. Sen stated that the traditional methods of famine analysis concentrated on the reduction in food supply as a primary cause of famines. His entitlement approach viewed certain commodities being the entitlement of individuals and that starvation is the failure to be entitled to any of these bundles. Sen's derivation of the famine analysis suggested that it was not the unavailability of food that led to the famine but the fear of an impending Japanese attack on the sub-continent which rendered the transportation dn communication channels inactive. The speculation related to the invasion led to price inflation leading to inaccessibility to the entitlement of the food products to the citizens.

It is postulated on similar lines that social exclusion or exclusion to certain commodity or service entitlements in life is not a primarily a function of unavailability of those commodities or services but a lack of access to those commodities or services [2]. Entitlement as an indicator of social inclusion and deprivation as an indicator of social exclusion is a direct derivation from Sen's theory. There are precedents of this conceptualisation in history.

Accessibility as a concept has been used in all fields of studies including social sciences, transport, medicine and politics. However, it is striking that the definitions of accessibility vary widely and are often not supported with succinct measures. Accessibility can be defined as the ease or ability of reaching goods and services. It can be evaluated from the perspective of group, mode, location or activity. Hence it is an important determinant of overall cost and investment towards availing goods and services.

This paper aims at exploring the social inclusiveness of the spatial plan or landuse plan in Bangalore city and thereby develop a framework for developing socially inclusive planning policy for the city. 


\section{SOCIAL INCLUSION AND SPATIAL PLANNING}

\subsection{Concept of social inclusion}

Human Rights and principals of equality and equity were the fundamental concept accepted in the 1995 World Summit for Social Development in Copenhagen. It has been recognised through various studies that education, economic stability, shelter and good health of individuals directly impacts the well-being of society. It has also been seen repeatedly in history that deprivation of basic services has been the cause of major social catastrophes, wars and political tensions. It is hence extremely important for policy makers to appreciate the impact of social inclusion. The necessity of adopting a socially inclusive approach to planning development is more important today than ever before [3]. In this paper we attempt at studying social inclusion in landuse planning or spatial planning, which is related to shaping of geographies.

\subsection{Measuring social inclusion}

Measurement of social inclusion is important for societies to assess their current accomplishment in providing a "society for all". It is of great importance to make sure that the efforts to provide social equality are not outrun by the greater economic and social forces affecting the society. The methodology to measure social inclusion adopted in this paper is by measuring the accessibility to social facilities. Employment, healthcare, education and housing are the basic social facilities. For the context of this study, employment or jobs has been considered the key social indicator which has been assessed for accessibility in the spatial plan of Bangalore city. There are various proposed theories of measuring accessibility, the following section discusses the accepted theories of measuring accessibility and the one adopted for this study [4].

\section{MEASURING ACCESSIBILITY}

The concept of accessibility has been used in various contexts for the last 50 years, hence literature pertaining to accessibility is huge. Literature provides us definitions of accessibility for individuals, location as well as activities. Accessibility is also a pertinent concept in transportation and spatial planning. There are three measurement approached that are widely accepted - people base, location based and utility based.

\subsection{Location based accessibility measures}

Location based accessibility measures were the first approach developed towards measuring accessibility. The approach measures the accessibility of a geographical unit for a transportation mode or facility. This mode can be used to measure effectiveness of new landuse or transportation projects for its impact on change of accessibility. This approach is effective in comparing the accessibility level of different zones with respect to a single transportation mode. It is also effective in comparing a single landuse based function between different zones. For example accessibility to jobs can be compared between zones by bus, car and metro and "well accessed" and poorly accessed areas can be identified. The cumulative opportunity measure and the Gravity Model come under this category of measurement. 


$$
X_{i}=\sum_{j}^{J} Y_{j} Z_{i}
$$

Eqn (1) represent the cumulative opportunity measure where $\mathrm{Xi}$ is accessibility measured at point $\mathrm{i}$ to potential activities in zone $\mathrm{j}, \mathrm{Yj}$ is the opportunities in zone $\mathrm{j}$, and $\mathrm{Zj}$ is a binary value equal to 1 if zone $\mathrm{j}$ is within the predetermined threshold and otherwise.

$$
X_{i m}=\sum_{j}^{n} Y_{i} f\left(Z_{i j m}\right) .
$$

Eqn (2) represent the Gravity model, where Xim is the accessibility at point $\mathrm{i}$ to potential activity at point $\mathrm{j}$ using mode $\mathrm{m}, \mathrm{Yj}$ is the opportunities at point $\mathrm{j}, f(\mathrm{Zijm})$ is the impedance or cost function to travel between $\mathrm{i}$ and $\mathrm{j}$ using mode $\mathrm{m}$, and $\mathrm{ijm}$ negative exponential function to travel between $\mathrm{i}$ and $\mathrm{j}$ using mode $\mathrm{m}$.

The cost of moving between the origin and destination determines the attractiveness of an opportunity. The further the distance of the destination the lesser is the attractiveness. The choice of impedance factors has a big impact in determining the attractiveness of an opportunity.

\subsection{Individual accessibility measures}

Though location-based measures are simple and effective as a tool to identify underserved areas, they come with certain constraints as they are not helpful in assessing non-home based trips or trips undertaken as a pert of trip chains. For example, trips undertaken in a chain like home - day-care - office - market - day-care - home are not suitable for assessment using the location-based measures. Individual accessibility measure are effective in such cases. Such approaches are based on extensive individual level travel data. Though accurate, these involve extensive data collection and are time consuming and privacy invading. Hence several GIS based models have been developed over the years incorporating the distribution of opportunities as well as the travel time variation to overcome the issues in the model [7][9].

\subsection{Utility based measures}

Utility based measure is one of the most accurate as well as data intensive and complicated ways to measure accessibility [10]. The measure of based on travel behavior theory based on macro-economic theory of user behavior. It says that a choice made by a person for one trip over another is directly dependent the utility drawn by the person for making that choice over another. The theory is consistent with the traditional microeconomic theory of consumer surplus that accessibility represents the benefits provided by transportation choices. It can be represented as

$$
S_{n}^{i}=1_{n}\left[\sum_{\forall e C_{n}} \exp \left(X_{n(c)}\right)\right] \text {, }
$$


where $\mathrm{Sj} \mathrm{n}$ is the accessibility measured for individual $\mathrm{n}$ at location I, $\mathrm{Xn}(\mathrm{c})$ is the observable temporal and spatial component of indirect utility of choice $\mathrm{c}$ for person $\mathrm{n}$, and $\mathrm{Cn}$ the choice set of person $\mathrm{n}$.

This approach is rarely used in comparative studies as it is difficult to compare utility functions between different neighbourhoods. It is also data intensive and complex in operation [11].

\section{CHOICE OF ACCESSIBILITY MEASURE}

There exists a number of ways to measure accessibility and it is important to select a method that best suits the purpose of the study. While the utility based approach best describes user behaviour it is challenging to compare different areas based on the process. The individual based accessibility measure is more accurate in measuring chain trips and non-home based trips it focuses on the accessibility of individuals to a particular function. The location-based measures are simple but are effective in measuring the accessibility of a particular locationbased utility against a particular trip mode.

The purview of this paper is to study access to employment through public transit and the approach is to understand the ease of access of a particular land unit offering job when trip is being made by public transit. Hence the location-based accessibility measures are found to be most suited to the study. The cumulative opportunity method is selected to simply the landscape as accuracy of the Gravity model would depend on correctly assigning the impedance factor. Impedance varies between neighborhoods and often dependent on economic as well as personal factors.

The Cumulative Opportunity Measure offers additional advantage of being scalability and operational ease. It is hence found to be most appropriate to for policy making decisions [11]-[13].

\section{OVERVIEW OF STUDY AREA: BANGALORE}

The location of study in the present paper is the multifunctional city of Bangalore known as the 'Silicon Valley of India'. Bangalore is the capital city of the state of Karnataka and is a hub of IT/ITES industries. The city was a prominent node in the erstwhile state of Mysore in medieval India and there after rose to take the character of an industrial town with the establishment and growth of the public sector engineering industries and aeronautical sector. It was once known as the 'pensioners' paradise for its salubrious climate and low scale developments. The mid 1990s saw the advent of the IT industry in the city. The industrial policy of the state along with other geographical factors propelled the establishment of Indian branches of major Silicon Valley players. The city is also an innovation hub and is known as the entrepreneurial incubation centre of the nation. As a result the city has attracted skilled and unskilled labour in the recent past.

Over the last 20 years the city has seen immense growth and has been growing at $4.2 \%$ per annum. It is one of the largest contributors to India's GDP (1.9\%). It houses $40 \%$ of the urban population of Karnataka and is one of cities with denser urban fabric. $46 \%$ of trips are by public transit.

\subsection{Planning process in Bangalore}

The spatial growth in India is statutorily planned in a document called the Master Plan. The Mater Planning process is guided by the Karnataka Town and Country Planning Act of 1965. As per the provisions of the Act, the city of Bangalore has a local planning area (LPA) known as the Bangalore Metropolitan Area. The spatial extent of the LPA is $1306 \mathrm{sqkm}$. A master 
Plan is prepared and revised every ten years. The present master plan of was prepared in 2007 and is known as the Revised Master Plan 2015 (RMP2015).

\subsection{Revised Master Plan 2015}

The Revised Master Plan 2015 (RMP2015) is a statutory document prepared to bring about guided development in the Bangalore Metropolitan Area. The plan identifies the long term growth perspectives of the city and lays out the blueprints in the form of landuse plans and Zoning Regulations. The RMP 2015 addressed long term sustainable development through directive principles including protection of nature, economic efficiency, social equity and historical heritage.

The population of Bangalore in the year 2007 was 6.17 million. It was projected that the population of the urban agglomeration would be 8.06 million by 2011 and 9.97 million by 2021.

For the purpose of this study, commercial, industrial and High Tech industrial (Information technology jobs) landuse are considered source of job creation in the city. The total area under commercial landuse is $19.18 \mathrm{sqkm}$, under industrial landuse is $44.26 \mathrm{sqkm}$ and under High Tech -industrial landuse is $54.53 \mathrm{sqkm}$.

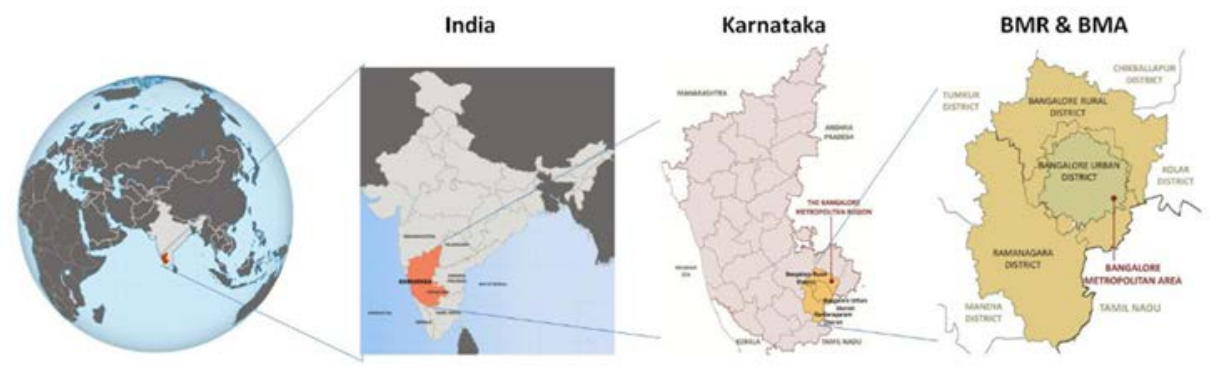

Figure 1: Location of the bangalore metropolitan area. (Source: revised master plan 2031 report.)
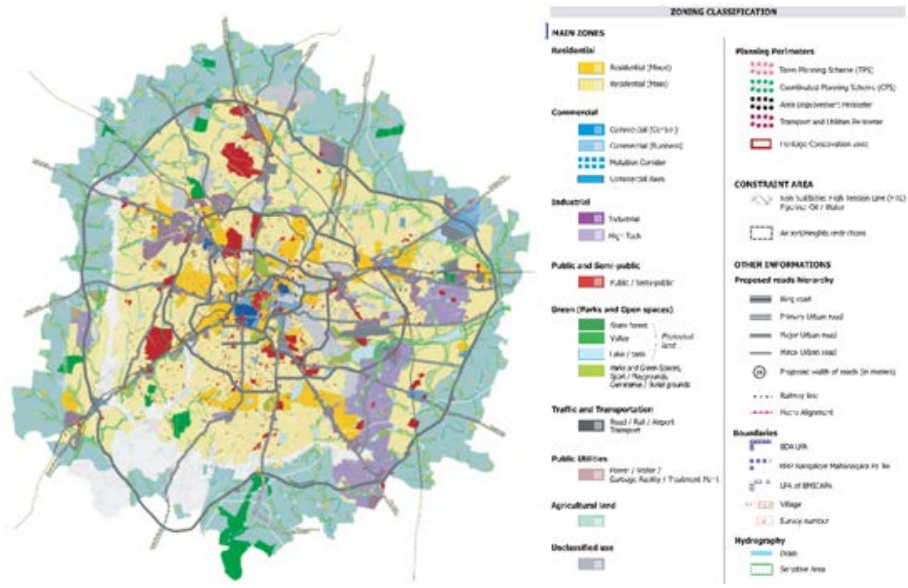

Figure 2: Proposed landuse map of RMP 2015. (Source Bangalore Development Authority.) 


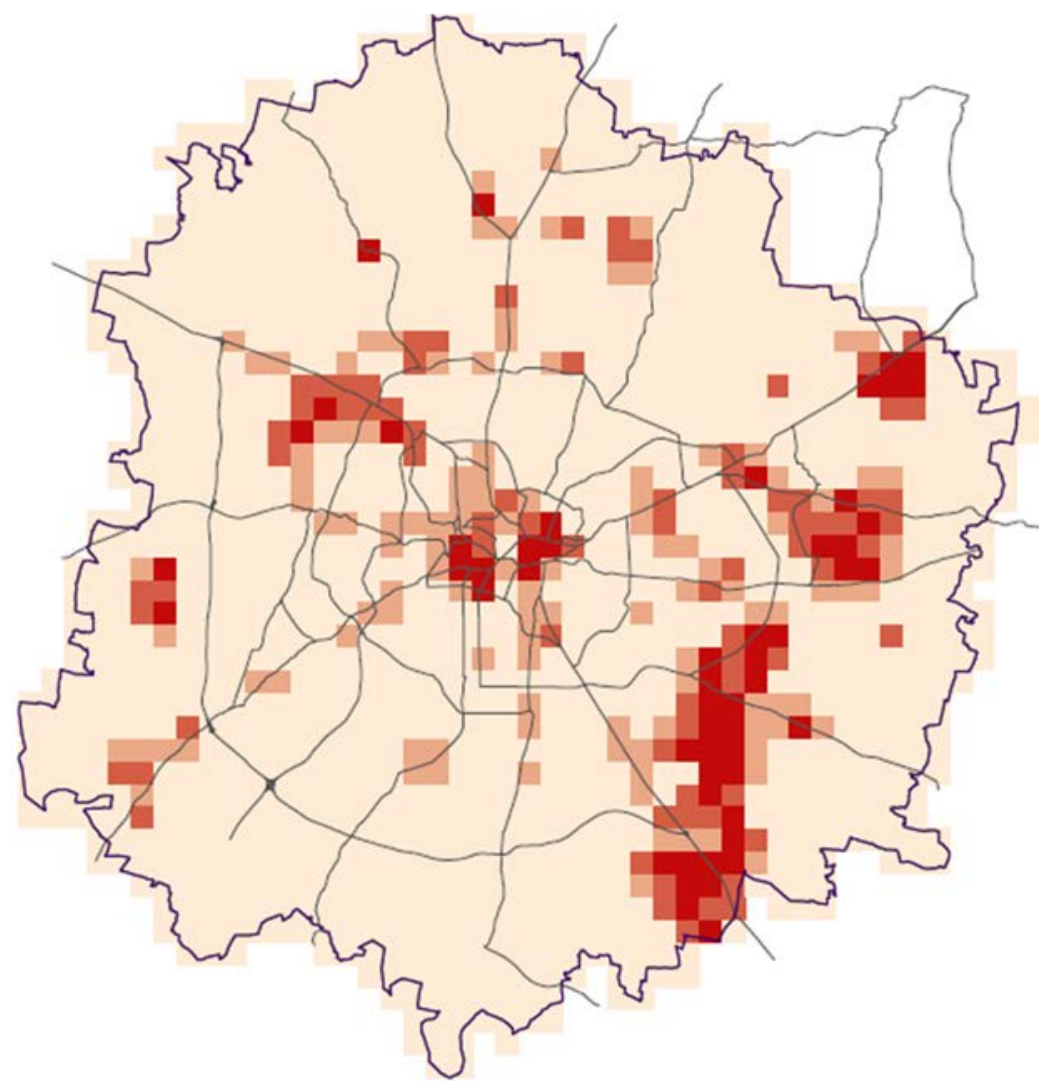

Figure 3: Potential Job density gradient in Bangalore.

In terms of job creation, the spatial plan has potential to create 4.21 lakh jobs in commercial sector, 5 lakh jobs in industrial sector and 6 lakh jobs in the High-Tech industrial sector. Jobs are calculated using area-employment ratio of 11,000 jobs per sqkm for industrial landuse and 22,000 jobs per sqkm for commercial landuse.

\section{MEASURING JOBS ACCESSIBILITY IN THE RMP 2015}

The master plan for Bangalore, i.e. the RMP 2015 is designed on GIS platform. Hence for the purpose of the current study, GIS software has been used to run analytical tools on the geodatabases. The circulation pattern i.e. the road network of road width greater than $12 \mathrm{~m}$ of the RMP 2015 has been extracted and added to the current geodatabase. The commercial and industrial landuse layers of 2015 proposed landuse has been included in the current database. Since bus transit and metro rail forms major share of public transport in Bangalore, the bus route and metro route network has been added to the geodatabase. The layer consists of routes as well as stops.

To evaluate accessibility of RMP 2015, a program is run to find commercial and industrial jobs within 10min walking distance or in a distance of $400 \mathrm{~m}$ from the bus stops and within $500 \mathrm{~m}$ of metro stations on all road networks. The results are described in the following sections. 
6.1 Opportunity to jobs by bus transit in revised master plan 2015

The results of the analysis tool show that $77 \%$ of all commercial jobs are accessible by bus transit while $67 \%$ of industrial jobs and $52 \%$ of hitech-industrial or the Information Technology jobs are accessible by bus transit. The map below shows the distribution of jobs along bus transit network.
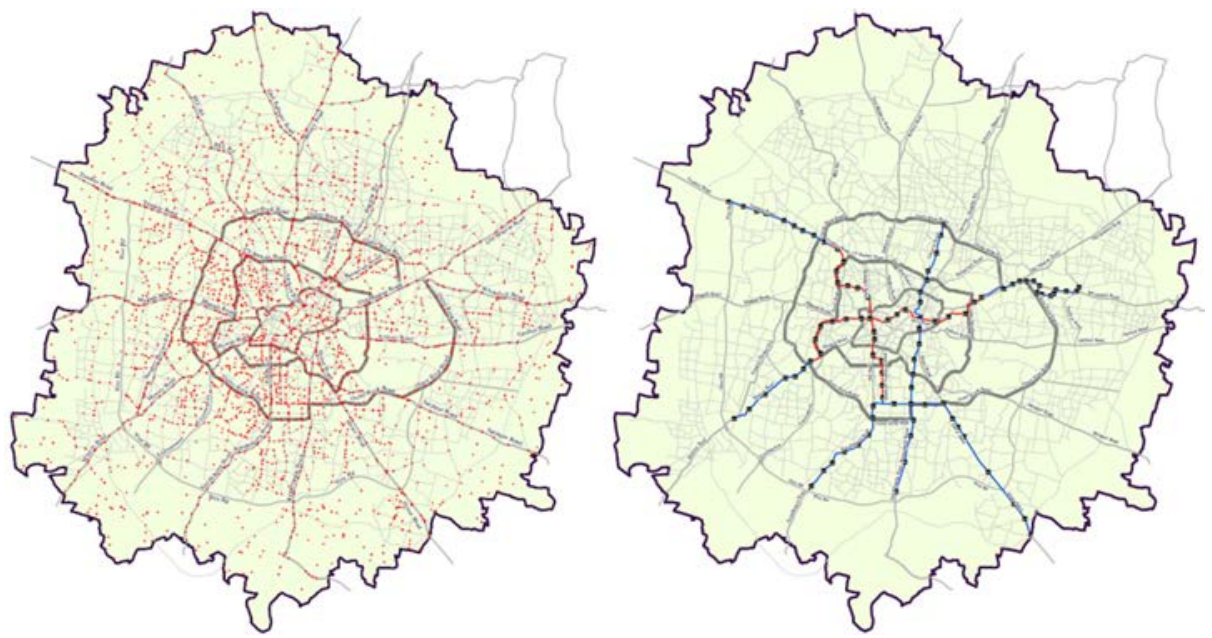

Figure 4: Bus stop and metro network in Bangalore.
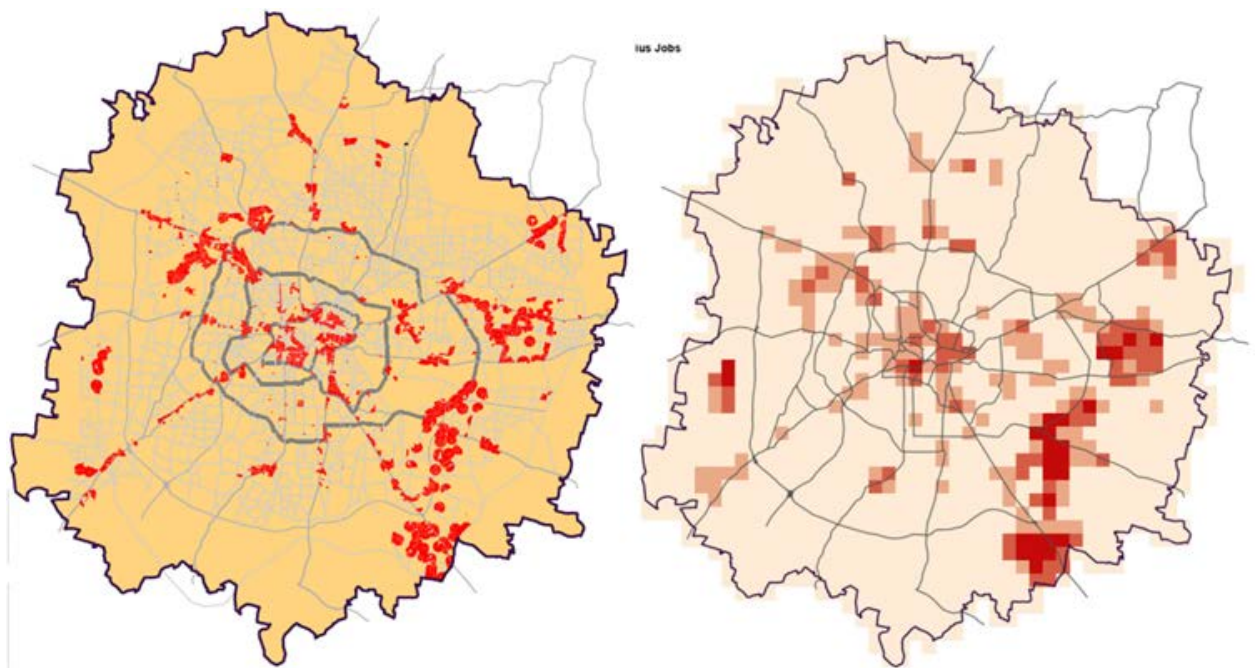

Figure 5: Distribution of commercial and industrial landuse and corresponding job density gradient in Bangalore. 

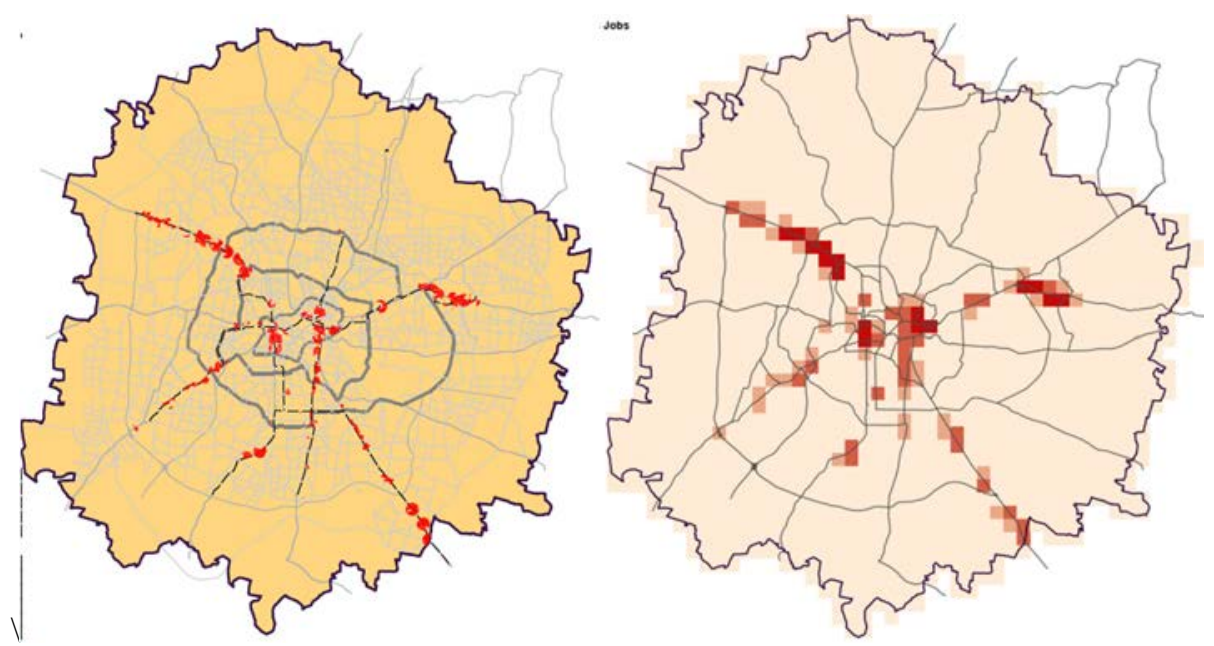

Figure 6: Opportunity to jobs via metro rail transit.
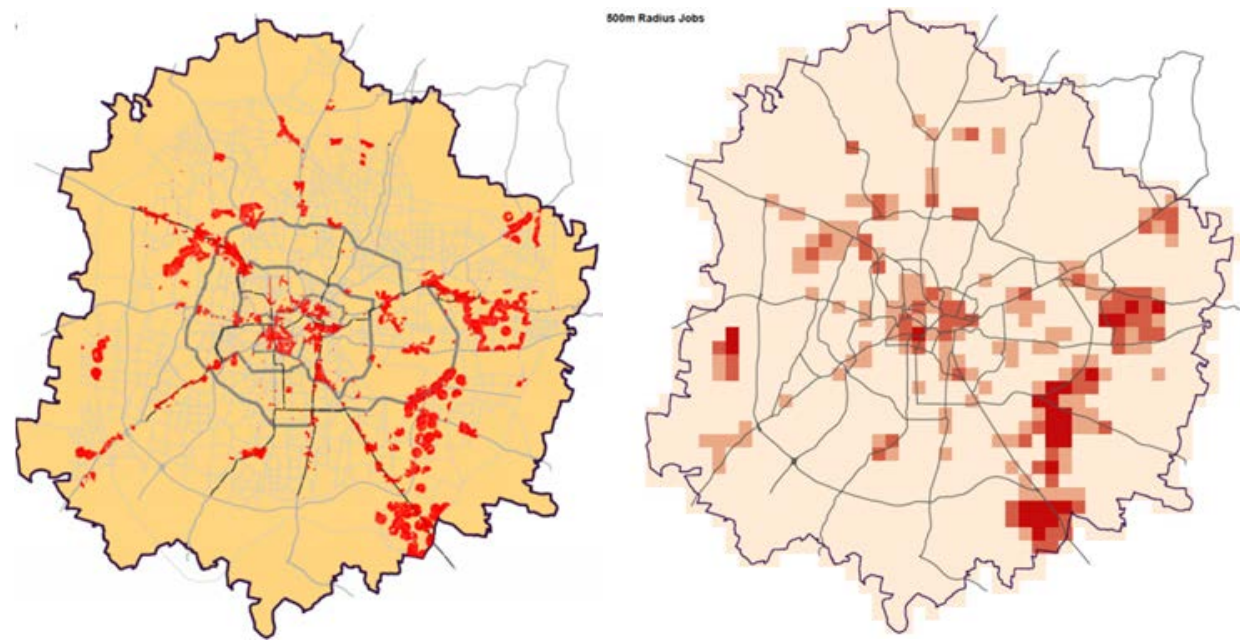

Figure 7: Cumulative opportunity to jobs via public transit.

\subsection{Opportunity to jobs by metro rail in revised master plan 2015}

The map above shows the distribution of jobs along the metro rail network in Bangalore. The results of the analysis tool show that $23 \%$ of all commercial jobs are accessible by bus transit while $18 \%$ of industrial jobs and $4 \%$ of hitech-industrial or the Information Technology jobs are accessible by metro rail.

\subsection{Cumulative opportunity by transit in revised master plan 2031}

The above map shows the distribution of jobs accessible by public transit in Bangalore. An analysis of the cumulative accessibility show that $79 \%$ of all commercial jobs are accessible 
by transit while $69 \%$ of industrial jobs and $55 \%$ of hitech-industrial or the Information Technology jobs are accessible by metro rail.

\section{TOWARDS A FRAMEWORK FOR SOCIALLY INCLUSIVE LANDUSE PLANNING POLICY}

The analysis of the jobs opportunity in Bangalore throws light on some key areas. It high lights an uneven spatial economic potential in the city where the eastern south-eastern arc of the city is more endowed than the rest. It also suggests greater travel cost and steeper housing rent gradient in parts of the city. The key industrial and the commercial areas are on the eastern-south eastern arc or are strategically placed in the outer areas of the city to create new growth nodes. The public transport system though equitably distributed in the old/existing city is unable to capture the potential of the newly planned job nodes. The bus and the metro rail have overlapping catchment areas and the potential of metro rail to provide fast and cheap access to new nodes have not been harnessed. The disconnect is the due to the disaggregated institutional structure for planning and transport provision. It appears that basic assumptions of future demographics, economic forecast and social trends are not uniform across the sectors. Last mile connectivity of public transport fails to capture the nodal geography of the industrial and commercial areas.

The framework for socially inclusive planning would essentially involve delineation of the goals for a socially inclusive city and any and all interventions would follow from the goals defined. The framework essentially involves a revitalisation of the planning process. India is a fast growing country and the pace of urbanisation out speeds the multiple institutions involved in planning and service provision. Hence there is a requirement for a central urbanisation framework for the city to establish uniform demographic, social and economic assumptions for the future. A trend analysis and predictive model for the city to forecast the spatial distribution of activities is desired. An econometric residential location module using rental gradient, housing supply and location and new land availability coupled with a transport module consisting of mode choice, trip length and cost would yield a predictive matric of spatial activity distribution maximising net economic benefits, social inclusiveness as well as environmental sustainability.

While it is not possible to have a single institution for operation and planning of varied sectors, achieving integration in planning assumptions is necessary to meet the goals. The spatial planning approach needs to create more balanced multifunctional city forms. An integrated approach towards the same is essential now to achieve the millennium goals of creating socially inclusive equitable and sustainable cities

\section{ACKNOWLEDGEMENTS}

This paper is based on the on-going related works in our organisation. I would like to thank my colleagues who have provided their time and energy in contributing to my research. I would also like to acknowledge with gratitude the support and love of my family, my husband Akash, my parents, Bimalendu and Tapati, my parents in laws, Hamsa and Mahesh and last but not the least my son Samak who keeps me smiling no matter what.

\section{REFERENCES}

[1] Sen, A., Poverty and Famines: An Essay on Entitlement and Deprivation, Clarendon Press: Oxford, 1981.

[2] Sen, A., Social exclusion: concept, application and scrutiny. Social Development Papers No 1. Manila: OYce of Environment and Social Development, Asian Development Bank, 2000. 
[3] Analysing and Measuring Social Inclusion in a Global Context, Department of Economic and Social Affairs, United Nation, United Nations publication, 2010.

[4] Atkinson, T. \& Marlier, E., Analysing and Measuring Social Inclusion in a Global Context, United Nations publication, 2010.

[5] Kwan, M-P., Murray, A.T., O'Kelly, M.E. \& Tiefelsdorf, M., Recent advances in accessibility research: Representation, methodology and applications. Journal of Geographical Systems, 5(1), pp. 129-138, 2003. DOI: 10.1007/s101090300107.

[6] Kwan, M-P. \& Weber, J., Individual accessibility revisited: Implications for geographical analysis in the twenty-first century. Geographical Analysis, 35(4), pp. 341-353, 2003. DOI: 10.1111/j.1538-4632.2003.tb01119.x.

[7] Miller, H.J., Measuring Space-Time accessibility benefits within transportation networks: Basic theory and computational procedures. Geographical Analysis, 31(1), pp. 187-212, 1999. DOI: 10.1111/gean.1999.31.1.187.

[8] Miller, H.J. \& Wu Y.-H., GIS software for measuring Space-Time accessibility in transportation planning and analysis. GeoInformatica, 4(2), pp. 141-159, 2000. DOI: 10.1023/a:1009820006075.

[9] Kwan, M.-P. \& Weber, J., Individual accessibility revisited: Implications for geographical analysis in the twenty-first century. Geographical Analysis, 35(4), pp. 341-353, 2002. DOI: 10.1111/j.1538-4632.2003.tb01119.x.

[10] Geurs, K.T. \& Wee, B.V., Accessibility evaluation of land-use and transport strategies: review and research directions. Journal of Transport Geography, 12(2), pp. 127-140, 2004. DOI: $10.1016 /$ j.jtrangeo.2003.10.005.

[11] Ben-Akiva, M. \& Lerman, M., Tradeoffs in residential location decisions: Transportation versus other factors, 1979.

[12] Geurs, K.T. \& Ritsema V.E., Accessibility measures: Review and applications. Evaluation of accessibility impacts of land-use transportation scenarios, and related social and economic impact, 2001.

[13] Geurs, K.T. \& Wee, B.V., Accessibility evaluation of land-use and transport strategies: Review and research directions. Journal of Transport Geography, 12(2), pp. 127-140, 2004. DOI: $10.1016 /$ j.jtrangeo.2003.10.005. 